\title{
DOENÇA DE HUNTINGTON EM PACIENTE SEM HISTÓRICO FAMILIAR - RELATO DE CASO
}

\section{HUNTINGTON DISEASE IN PATIENT WITH NO FAMILY HISTORY - CASE REPORT}

Gustavo Henrique De Morais Pinheiro*, Janara Caroline Bertoli Yoshii, Heitor Teixeira Marcon Junior, Isabela Fernanda Ribeiro Fernandes, Ingrid Canales Staub De Barros, Isis Lettícia Castanheira Rosa, Sérgio Augusto Buchweitz.

'UNINGÁ - Centro Universitário Ingá, Maringá, PR, Brasil. *gugshenrique10@gmail.com

\section{RESUMO}

A doença de Huntington (DH) é uma doença monogénica neurodegenerativa transmitida por herança autossômica dominante com penetrância completa, com prevalência de 5-10 casos por 100.000 habitantes no Brasil. Sua etiologia está implicada na repetição exagerada do trinucleotídeo CAG no braço curto do cromossomo 4(4p16.3), sendo caracterizada por sintomas psiquiátricos (agitação, agressividade, depressão, mania, delírios e alucinações), motores (coreia, rigidez, bradicinesia, distonia) e cognitivos progressivos (desordens de aprendizagem). O objetivo do presente estudo é relatar um caso de $\mathrm{DH}$, seus aspectos epidemiológicos, diagnósticos e terapêuticos. EF, masculino, 42 anos, foi encaminhado ao Ambulatório de Neurologia devido as seguintes queixas relatadas pela mãe, sua informante: (1) alteração do comportamento e da (2) motricidade, (3) instabilidade postural e (4) quadro demencial. Ao exame neurológico, foi observada rigidez simétrica, disdiadococinesia, aumento de reflexos bilateralmente, dismetria índex nariz, sinal do rechaço bilateral e exoftalmia. RNM de crânio do paciente de julho de 2020 trazida pela mãe evidenciava redução volumétrica encefálica difusa e homogênea; ectasia compensatória do sistema ventricular e importante atrofia neoestriatal bilateral. Segundo a mãe, por volta dos 23 anos, EF iniciou quadro de irritabilidade, depressão e heteroagressividade, apresentando múltiplas parceiras sexuais e etilismo, sofrendo internações pela dependência alcoólica. Aos 29 anos, foi diagnosticado com Síndrome do Pânico, sendo tratado por dois anos com posterior abandono do tratamento. Aos 35 anos, houve piora importante da agressividade e mudanças comportamentais, necessitando de internações recorrentes. Há dois anos, EF iniciou episódios de queda da própria altura, movimentos involuntários, dificuldade para deambular, falar e deglutir, além de tornar-se tabagista; com piora progressiva importante do quadro motor, cognitivo-comportamental e da irritabilidade há quatro meses. Assim, mãe de EF buscou atendimento para investigação do quadro, sendo solicitado estudo genético para $\mathrm{DH}$, cujo resultado veio positivo para a doença, com presença de alelo com 17 repetições de CAG e outro com 49 repetições CAG. Segundo a informante, não há histórico familiar materno de doenças neurológicas ou psiquiátricas; por parte paterna, a mãe desconhece histórico patológico. Atualmente, o paciente encontra-se em tratamento com Olanzapina $10 \mathrm{mg} / \mathrm{dia}$, 
ácido valproico $500 \mathrm{mg} /$ dia e Diazepam $10 \mathrm{mg} /$ dia com controle dos sintomas. A partir do presente relato, conclui-se que a $\mathrm{DH}$ é diagnosticada ambulatorialmente através de anamnese associada ao exame físico, investigação com exames de sangue e neuroimagem. O manejo ambulatorial desta afecção rara, atualmente sem possibilidade de cura, visa melhorar a qualidade de vida do paciente nos diversos níveis de complexidade da atenção à saúde.

Palavras-chave: Doença de Huntington. Doenças raras. Proteína Huntingtina. Testes genéticos. Transtornos mentais. 